\title{
The semiotic ecology of linguistic landscapes in rural Zambia
}

\author{
Felix Banda and Hambaba Jimaima
}

\begin{abstract}
In addressing the dearth in studies on linguistic/semiotic landscapes in orallanguage dominant rural communities, we use the notion of repurposing to show how people from rural areas of Livingstone and Lusaka in Zambia (SouthCentral Africa) extend the repertoire of 'signs' to include faded and unscripted signboards, fauna and flora, mounds, dwellings, abandoned structures, skylines, and village and bush paths (with no written names) in narrations of place. We illustrate how they use the system of signage to transcend the limitations of the material conditions in the rural-scapes by redeploying memory, objects, artifacts and cultural materialities in place to new uses, and for extended meaning potentials. We conclude that focusing on the semiotic ecology in multimodal linguistic/semiotic landscapes helps to accentuate the multisemiotic and diverse processual characteristics of meaning-making, even in areas that do not have scripted place and street names.
\end{abstract}

\section{Introduction: remediation as repurposing}

In this article we focus on linguistic/semiotic landscapes in rural areas in which oral language plays a significant remediating role in the production and consumption of signage. Of particular interest is how oral language is used in the narration of place through realigning semiotic material such as trees, hills, bush paths, physical objects (e.g. rocks, concrete blocks) and faded signs for multiple purposes. Considering the few emplaced public signs generally, and/or absence of written signage in particular: how is signage produced and consumed in these rural-scapes? What linguistic/semiotic ecology of landscapes is available in these rural-scapes? To what extent is the production and consumption of signage in these rural-scapes similar or different from that found in urban areas? The analysis of linguistic/semiotic landscape data from some rural areas of Lusaka Province and the Southern Province of Zambia gives us the prospect not only to illustrate different aspects of 'remediation,' but, in particular, what Bolter and Grusin (2000: 89) call 'remediation as repurposing' of, in this case, semiotic material in the oral narrations of place in the rural areas under study.

Research in linguistic/semiotic landscapes reveals a bias towards urban areas (Zabrodskaja and Milani 2014) dominated by Western type 'reading' culture, sign making and consumption. A walk in the urban-scapes for consumers means navigating through planned streets and/or roads, often lined with buildings, trees, 
flowers, scripted road or street signs and often carrying illuminated signage on buildings and billboards. Although there are overlaps with urban areas, the production and consumption of signage in rural areas of Africa is in many respects different. The difference arises from the fact that in most rural parts of Africa, for example, there are very few or no planned community streets, roads, buildings, trees, flowers, road or street signs, and no signage on buildings and no billboards. Additionally, in these rural spaces of Africa the presence or absence of fauna and flora is more often a consequence of nature rather than planned human activity. All these lay constraint on the material conditions amenable for consumption as well as narration of place in rural areas.

\section{Operationalizing repurposing}

The notion of remediation has been used in many different ways (Vandenbussche 2003; Irvine 2010; Prior and Hengst 2010). As Vandenbussche (2003: 1) notes, using the notion of remediation requires one 'to describe accurately to which substance the term is referring.'

In a number of studies, remediation has referred to 'multimodality and transfers among media' (Irvine 2010: 236). Further, Prior and Hengst (2010) have noted that studies on remediation have included those on mediated discourse analysis (Scollon and Scollon 2003), media intertextualities (Hiramoto and Park 2012), notions of intertextuality and interdiscursive chains (Fairclough 2003), notions of entextualization (Briggs and Bauman 1992; Silverstein and Urban 1996) and resemiotization (Iedema 2003), and Bernstein's (2000) and Linell's (1998) notion of recontextualization. These studies have enabled analysis and understanding of how materials and activities are represented across modes, media and chains of mediation. Similarly, recent studies on semiotic landscapes, such as Thurlow and Jaworski (2014) and Stroud and Jegels (2014) that have focused on multimodality, have used the notion of remediation in various ways. Stroud and Jegels (2014) have demonstrated oral remediation of semiotic landscapes in their study of personal narratives of place in Manenberg, a township in Cape Town, South Africa. Thurlow and Jaworski (2014: 459) have used the notion of remediation in their analysis of a variety of verbal (spoken and written), nonverbal (gesture and movement) and technological (photography and video) materials used by tourists at the Leaning Tower of Pisa. They use the notion of remediation to show aspects of 'recycling and layering of mediatized representations (e.g. guidebooks and official brochures), mediated actions (e.g. climbing the Tower or posing in front of it), and remediated practices' (2014: 459). The resulting shape of media and related narratives are transformative of the tourists themselves, who become integral parts of the tourist attractions (objects and events) they came to experience; it also transforms the tourist place itself, which is reinvented for consumption through home-video viewing or for sharing on YouTube.

Most of the studies on remediation have focused on 'the influence of new media on culture in general and on the relation towards the already existing media in particular' (Vandenbussche 2003: 1). Following Bolter and Grusin (2000), we illustrate the ways in which remediation as repurposing, henceforth 
repurposing, can be used as a conceptual tool in the field of linguistic/semiotic landscapes. Following Prior and Hengst (2010) and Irvine (2010), we operationalize the notion of repurposing to capture and underline the agentive nature of human-sign-environment interaction, and hence on the 'ever-emergent social relations, and on the ways semiotic forms can serve as resources for social agents' for multiple purposes (Irvine 2010: 236). Prior and Hengst (2010) and Irvine (2010) maintain that although a reproduction of an oral report into a reported or written form can be said to be remediation, it does not necessarily entail repurposing. Bolter and Grusin (2000: 47) critique McLuhan's (1964: 23-24) remark that 'the "content" of any medium is always another medium. The content of writing is speech, just as the written word is the content of print...' by contending that McLuhan was not referring to repurposing. They argue he was referring to remediation without repurposing; a kind of 'borrowing in which one medium is itself incorporated or represented in another medium' (Bolter and Grusin 2000: 45). Repurposing as conceptualized in this article, occurs 'even if their semiotic modality itself does not change' (Irvine 2010: 236).

Following Bolter and Grusin (2000), we derive two aspects of repurposing. First, in illustrating 'remediation as repurposing,' Bolter and Grusin (2000: 68) cite 'pouring a familiar content into another media form; a comic book series is repurposed as a live-action movie, a televised cartoon, a video game, and a set of action toys.' Repurposing is, in this case, understood as recycling of material or content from one medium in another medium for a different purpose. Bolter and Grusin (2000: 68) are quick to point out that the idea is not to replicate the earlier forms but to exploit new meanings that claim 'to offer an experience that the other forms cannot.'

It also the case that for Bolter and Grusin (2000: 68) repurposing is not confined to media relationships; it is also about the 'refashioning of materials and practices' as well as the creative 'borrowing and adapting [of] materials and techniques whenever possible,' for new meanings and purposes. Thus, in addition to contributing to the analytical tools of the study of linguistic/ semiotic landscapes, we extend the interpretation of the notion of repurposing beyond the relationships between old and new media cultures, to the recycling and reusing of objects, memory and cultural materialities for sign- and place- making, generally.

Therefore, in exploring sign- and place-making in rural communities of Zambia, we recognize 'the simultaneous, layered deployment of multiple semiotics (talk, gesture, artifact use and production, interaction with environmental structure)' (Prior and Hengst 2010: 19). We recognize it not just as semiotic material in narratives of remediation, but also as semiotic resources amenable to be repurposed as embodiments of new activities, material artifacts, sociocultural experience and aspirations with multiple meaning potential in an individual's or community's life-worlds. One consequence of repurposing is that the altered material conditions, due to the reinvention of the semiotic environment, frames the production and consumption of linguistic/semiotic landscapes as 'dialogic, not generated out of abstract systems, but drawn from a history of sign use, tuned to the present interaction, and oriented to future responses and acts' (Prior and Hengst 
2010: 7). In turn, the subsequent infusion of new purposes and meanings to semiotic material in place entails the creation of new contexts in which future references, meanings and re- and co-relationships of activities and semiotic relations will be produced and consumed. The notion of repurposing expands the meaning potential of semiotic material and repertoires of texts in what Shohamy and Waksman (2009) call an ecological arena. The linguistic/ semiotic ecology is, in this case, constituted by the mutual relationships between the interactants themselves, and their co- and inter-relation with the environmental semiotic material (Shohamy and Waksman 2009; Pennycook 2010).

The remainder of this paper is organized in five main sections as follows: first, the paper describes the setting of the study with a view to highlighting the linguistic situation and geographical situatedness of the selected rural parts of Zambia. Thereafter, we provide an overview of the theoretical underpinnings of the material culture of semiotic landscapes and the linguistic/semiotic ecology of landscapes, respectively. We later discuss the methodology, followed by data analysis in which we show how the creative oral narration and repurposing of semiotic materials function to extend the range of the meanings and purposes within the linguistic/semiotic ecology of landscapes. The last section summarizes and concludes the article.

\section{Material culture of semiotic landscapes}

In its original conceptualization, linguistic landscapes (LL) is institutionalized in the famous definition by Landry and Bourhis (1997: 25) as '[ $t$ ] he language of public road signs, advertising billboards, street names, place names, commercial shop signs, and public signs on government buildings ....' While some of the research on LL still uses Landry and Bourhis's (1997) definition of the LL as a starting point (for example, Backhaus 2005; Cenoz and Gorter 2006), more recent works have expanded the conceptualization of LL. Shohamy and Gorter (2009) called for the inclusion of other semiotic resources in the construction of the LL, while Jaworski and Thurlow (2010) propose that the field of study should be on semiotic landscapes rather than on LL to account for the multimodal nature of landscaping. These calls to expand the 'scenery' of LL entail many things. They range from methodological issues on what should constitute as data in the LL, to how these data should be collected and analyzed on the one hand, and which theoretical appraisal should inform such undertakings on the other hand (Pennycook 2009, 2010; Stroud and Mpendukana 2009, 2010; Jaworski and Thurlow 2010; Stroud and Jegels 2014; Zabrodskaja and Milani 2014). With the expanded 'scenery' is the question of whether the field of study should be called linguistic landscape or semiotic landscapes. However, following Zabrodskaja and Milani's (2014: 1) convincing argument that 'linguistic landscape has not only gained currency as a key theoretical notion in the study of the sociology of language; it has also established itself as a strand of academic inquiry in its own right,' we shall default to linguistic/semiotic landscape when referring to the general expanded theoretical notion, and use LL or semiotic landscapes to refer to specific aspects. 
In broadening the scope to the study of linguistic/semiotic landscapes, recent studies have drawn from diverse disciplines for complementary and supplementary notions and concepts. In arguing for expansion of the current epistemological models of linguistic landscape research, Aronin and ÓLaoire (2012: 1) call for a 'focus on materialities that are linked with the ways of life in ... homes, places of work and socialization and time-spaces of wider society.' In this connection, rather than the 'commonly used analysis of public space texts' (2012: 2), Aronin and ÓLaoire outline what they call the material culture of multilingual landscapes. They claim that everyday life objects and 'physical items, produced by humans as well as events and spaces interconnected by and with local and global mentality, culture, tradition and social life' (2012: 3) are critical components in linguistic/semiotic landscape studies. The notion of material culture has been used productively by archaeologists, historical geographers and ethnographers, not only to 'scrutinise the qualities of artifacts, the use and production of objects and to compare them,' but most importantly, it has been used as a tool to compare 'the position of investigated artifacts in space and how they are located in relation to each other (e.g. left, right, on top of the other, etc.)' (Aronin and ÓLaoire 2012: 3). The notion of material culture helps to conceptualize and to add value to the present article as it foregrounds human interaction with the material world in which sign-making is not just about written language or visible objects in space; it is also about the reimagination of ideas, shared knowledge of socio-cultural history and natural artifacts, and their reinvention in narrations of place. Zabrodskaja and Milani (2014: 1) echo these sentiments when they observe that recent scholarship on linguistic/semiotic landscapes takes 'a phenomenological, post-humanist orientation that is not limited to critical analyses of public texts per se. Instead, the emphasis is on understanding the human-sign interface ....'

However, although there is considerable movement in expanding the scope and depth of linguistic/semiotic landscape studies, Zabrodskaja and Milani (2014: 2) remind us that recent work on linguistic/semiotic landscape studies have not progressed in a linear order; there has been an apparent movement in circles forwards and backwards - the shift towards qualitative analysis and right back to quantitative analysis. Zabrodskaja and Milani (2014: 1) also point out that studies of linguistic/semiotic landscapes in rural areas are 'extremely rare,' comprising only one out of nine articles in their journal special issue. This bias is understandable, as studies have been based in contexts with a certain degree of writing and reading culture, which most often inevitably means urban areas or towns. Yet, as Pennycook (2009: 308) notes, following Schama (1995) and Cannadine (2000: 188), landscaping should be seen as 'what culture does to nature.' The cultural experiences and materialities in urban areas are not exactly similar to those in rural areas.

Generally speaking, rural and urban cultures may produce and consume signage differently. The significance of this is that it brings home the argument that in rural areas of Africa, for example, with limited or no written culture in place, landscaping is not just about visible semiotics (in the sense of scripted language, graffiti, signboards and signage on buildings and vehicles). It is more about how natural 
objects such as trees and hills, socio-cultural knowledge systems and related sentiments, feelings and memory, are orally remediated as everyday 'conscious acts of landscaping ...' (Cannadine 2000: 188, as cited in Pennycook 2009: 308). In essence, although oral narration takes place in urban areas, the cultural and material contexts surrounding its production and consumption are different from those in rural areas. Narration of place in urban settings can make reference to neon lights, scripted language, graffiti, signboards and signage on buildings, vehicles and so on, while narration of place in rural areas may require additional or intricate oral input in repurposing natural objects such as trees, hills and bush paths as semiotic materials for sign and place-making.

\section{Linguistic/semiotic ecology and landscapes}

The notion of 'ecology,' as used in linguistics literature, cannot easily be placed in a single-watertight paradigm as it means different things to different scholars in both usage and application. It is easy to notice this ambivalence with a quick survey of the literature. In 1970, in Einar Haugen's paradigm of the ecology of language, the focus was essentially on a 'new ecological study of the interrelations between languages in both the human mind and in multilingual communities' (Fill and Mühlhaüsler 2001: 1; Haugen 2001). In this sense, the concept of 'ecology,' as Fill (2001: 44) reminds us, 'is understood metaphorically and transferred to language(s) in an environment' and the metaphor of language ecology 'continues to be used, particularly in the study of minority languages and language imperialism .....' This metaphoric use of ecology underpins language diversity in the linguistic ecosystem and the implication of the diversity to the 'urgent problem of language endangerment' (Fill and Mühlhaüsler 2001: 2; see also Mühlhaüsler 1996). Plainly, Fill and Mühlhaüsler (2001: 4) concede that 'diversity or, better, structured diversity is a defining characteristic of all functioning ecologies.' It can be seen from the foregoing that language ecology as used in these works broadly relates to how languages maintain their vitality given the complex linguistic/language diversity in the 'environment' of language. This explains in part why recent works on language ecology have tended to emphasize topics dealing with endangered minority languages.

In recent works on linguistic landscapes, notions such as linguistic economy and language ecology have gained currency. Ecology in LL studies parallels the metaphoric use of the concept described above. Cenoz and Gorter (2009: 62), for example, in their discussion of Language Economy and Linguistic Landscape, make reference to 'ecosystems' by pointing out that 'diversity is necessary for evolution and the strongest ecosystems are those which are more diverse.' They further remark that ' $[t]$ he disappearance of a species is a great loss for the world but the death of a language is also a significant loss because languages imply a loss of inherited knowledge' (2009: 62). In this sense they privilege the bio-diversity invested in languages. Hult (2009) follows suit in framing his study of Language Ecology and Linguistic Landscape Analysis after the notion of language diversity. He reminds us that the core principles of the ecology of language [h]as an orientation to multilingualism' (2009: 88). Given the object of study in mainstream LL, such as photography and the presence of specific languages observable on the signage and 
how these languages appear on signage, Hult (2009: 91) concludes that these make the LL study 'an ecological approach to the study of multilingualism' as it provides 'a window into the niches of specific languages in a linguistic ecosystem.'

In this paper, however, the notion of ecology is extended beyond languages in contact to account for the multimodal turn in linguistic/semiotic landscapes studies. We use it to capture the productive and complex interplay between the diverse semiotic material in place, to which meanings are assigned and appropriated based on the circumstance of use and its consumers. Particularly, a focus on the ecology of semiotic material in place is meant to privilege and highlight the creativity of producers and consumers of the semiotic material, who selectively use memory, historical knowledge, the natural features in the environment, spatial architecture and cultural materialities (Aronin and ÓLaoire 2012) to bring to life diverse meanings relating to the spaces they navigate. This prioritizes the interactions between producers and consumers of signs, and the varied semiotic material in place. Shohamy and Waksman (2009: 314) perceive a study of the semiotic ecology of linguistic/semiotic landscapes in the sense of the dynamic relations between 'verbal texts, images, objects, placement in time and space as well as human beings.' Citing Kress and Van Leeuwen (2006), Iedema (2003) and Scollon and Scollon's (2003) 'geosemiotics,' among others, Shohamy and Waksman (2009) argue for the broadening of the repertoire of texts to capture the expanded meaning potential as a result of the interplay of multiple semiosis in the semiotic landscapes. We follow Shohamy and Waksman (2009) and Pennycook's (2010) characterization of linguistic/semiotic ecology, in which the interlocutors, the spatial design, the visual, the audio, the gestural, olfaction, linguistic and generally the multisemiotic materials in place are brought together for different shades of meaning. The notion of 'ecology' is thus used akin to Shohamy and Waksman (2009) and Pennycook (2009, 2010) to emphasize the semiotic diversity in the ecosystem/environment constituted by multimodal material in the landscapes from which multiple meanings are produced and consumed.

\section{Contextualizing rural Zambia}

Zambia is a landlocked country located in South-Central Africa. It shares its borders with Zimbabwe on the southern part, Mozambique on the southeast, Malawi on the eastern side, Botswana on the southwest, Angola to the west, Tanzania to the northeast and Congo DR on the northern part. Our interest is in the rural areas of Livingstone, namely, around Mukuni village, which stretches between Livingstone and Zimba towards Lusaka in the north, and Livingstone and Kazungula bordering Zimbabwe and Botswana in the south. In Lusaka Province, the interest is in the rural district of Chongwe, which is about 35 kilometers east of the Lusaka central business district.

The conceptualization of 'rural' in the Zambian context is based on the distance between a given area and the main post office. This is the criterion used for awarding a rural-hardship allowance to government employees in Zambia. Usually, an area situated at a distance exceeding 10 kilometers from the post office is considered rural. 
However, this criterion is, in most cases, subjective as one may find an old post office in some areas designated as rural by government. Thus, the mere presence of a post office may not index an area as urban. Against this background, the article takes 'rural' to represent areas which are without such amenities as hydroelectricity, modern shopping complexes, piped water and other social amenities found in urban areas.

The Central Statistical Office of Zambia (CSO) shows that, at 61.9 percent, Nyanja is the most widely spoken language in Lusaka Province (CSO 2010). In the Southern Province, Tonga is the most widely spoken language at 74.7 percent.

\section{Methodological issues}

Stroud and Jegels (2014: 180) suggest 'walking narrative methodology' to account for the complex dynamics of place-making, which, they argue, involves the investment of social and affective capital of individuals tied to, identifying themselves with or moving through a particular locale.' In turn, building on the work of Thrift (2007) and Pietikäinen et al. (2011), Stroud and Jegels (2014) further propose a methodological turn which emphasizes the performative nature of semiotic landscapes, and in which semiotic landscapes are seen as transmodal and corporeal in nature. The consumption and production of semiotic landscapes is nascent and processual (Stroud and Jegels 2014). Citing Pietikäinen et al. (2011), Stroud and Jegels (2014) comment that place making and visual space are consequences of human interactions, which also affect human activities.

Moreover, following Mondada's (2011) praxeological approach to place-making and Urry's (2005) mobility in local place-making, Stroud and Jegels (2014) suggest the need for emphasis on human social action and on how signage is construed, (re)imagined and embedded in local narratives of place. Here, we see their work as a highlighting the production and consumption of locality as 'organized, narrated, and interactively accomplished by means of - direct or indirect - engagement with situated material semiotic artifacts' (Stroud and Jegels 2014: 180). Building on the performativity and materiality of place making (Stroud and Jegels 2014) and works by Massey (2005), McIlvenny, Broth and Haddington (2009), and Lefebvre (1991), we adopted the walking methodology tool, which enabled us to 'monitor the enactment of discourses of place as they evolve over time and across landscapes through the perspectives and affectual stances of narrating walkers' (Stroud and Jegels 2014: 183).

The linguistic/semiotic landscape typologies developed for urban areas that have planned streets and signposted roads and signed business centers with billboards and scripted walls and windows and merchandise, may not apply in rural-scapes as the landscape is laden with unplanned housing, small winding paths and fens. Although occasionally one found a river, mountain or village path or other natural object demarcating villages, it became pointless for us to use such 'borders.' Only a few 'knowledgeable' local people have oral discursive narrations (rather than written maps) about where one village stopped and another started. Granted, as noted 
above, that a headman normally heads a village and a chief may have several headmen, and hence several villages under his/her jurisdiction, this unitary confederacy does not presuppose a linguistically homogenous society, nor does it entail an objective discursive construction of where one village stops and another starts. The diversity in the ethnolinguistic and demographic composition of these enclaves - for example, the presence of white farmers, Indian and West African shop owners, educated and uneducated, young and old, literate, semi-literate and illiterate, male and female, and retired citizens, some of whom are originally from different parts Zambia - brings to these rural-scapes the use of rich and creative communicative strategies to compensate for (lack of) literacy for some of the citizens, common language in some cases and lack of written language on the public signs generally. In part, it could explain why we found that even retired teachers, civil servants, accountants, etc., defer to oral linguascaping in the rural environment.

We used a digital camera to capture images of the rural districts of Lusaka and Southern Provinces to collect 1,500 tokens, and we also did participant observations and collected walking interview narratives from some patrons of the study areas over a period of four months, from May to August of 2014. Specifically, the data were collected from two research areas - rural Chongwe, an area east of Lusaka Central Business District and Livingstone rural, an area between Livingstone Central Business District and Kazungula district. A total of 15 walking interviews were conducted with the locals in each of these rural areas. These interviews provided qualitative data related to the interviewees' memory and processes in the 'human making ... and shaping' (Pennycook 2009: 308) of the landscapes, while the digital images of the rural-scapes were meant to capture the sort of objects and artifacts (man-made or natural) around which oral narratives revolve to give meaning to various human endeavors and material culture (Aronin and ÓLaoire 2012). In executing the walking interview as a means of data collection, one of the researchers would 'walk' to a particular place (e.g. a market place/playground) and ask questions relating to it and surrounding areas. Or he would ask for directions to 'some' location within these rural environs and request that he be accompanied by the interviewee in the 'walk' as a way of eliciting information about the construction and consumption of space (Stroud and Jegels 2014). The researcher would note how the individuals were constructing the landscape from socio-cultural and historical knowledge and memory, and to which elements or features they referred in order to navigate the place. Questions such as: 'How do I get to the next village?'; 'How do I get to the chief's palace?'; and 'How do you traverse the landscape without signage?' were used to elicit information from the dwellers of these environs. How the direction was given and the features pointed at, from memory/historical knowledge and/or in physical space, provided useful insights into the production and consumption of signage in place. The meanings that the social actors on these rural-scapes apportioned to different semiotic features, such as those without written language, were noted during interaction. During such walks, the researchers came face to face with real situations in which semiotic resources in circulation were in use. In this way, the researchers also witnessed and participated in the eventual reconstruction and consumption of semiotic landscapes in place. 


\section{Repurposing and semiotic landscapes in rural-scapes}

In the rural-scapes we visited, there were no discernible streets. This offered little or no place on which to emplace or write a sign. Some signboards were blank while others had faded to illegibility. It is also interesting that in some cases the written language, albeit in local languages, was ignored in giving directions, with people opting to give their own oral linguascaping of the environment based on sociocultural and historical knowledge and particular landscapes in the environment. Repurposing of semiotic material is not always obvious but becomes evident with careful analysis of the historical, socio-cultural and economic contexts surrounding the production and consumption of the signage.

Studies in linguistic/semiotic landscapes have shown that some shop owners may display signage in English, Chinese, Japanese and so on, to attract potential customers even though they do not speak the language (Lanza and Woldemariam 2009; Malinowski 2009; Peck and Banda 2014). In Livingstone, a Chinese businessman who does not speak or understand any Tonga is still able to use the language for the production of the LL of his lodge, as shown in the image in Figure 1. 'Pumuna' is a Tonga word for 'rest'. The use of Tonga and Chinese interfaces two identities couched by cultural and ethnolinguistic mobility in the transnational world. Underneath the Tonga-English message he has inscribed a Chinese text, which means "A feeling of going back home in the "inn" or "family-like inn."

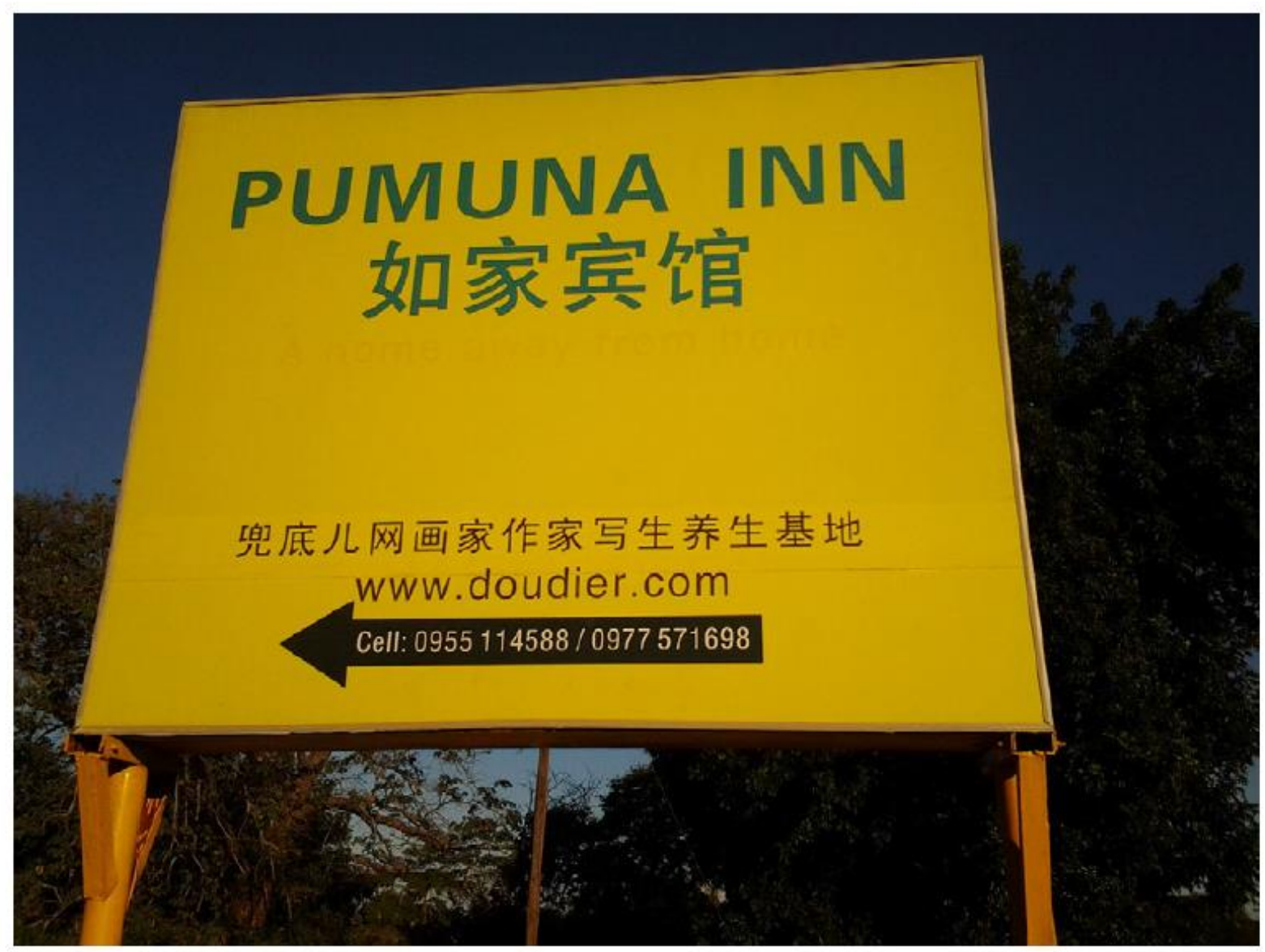

Figure 1: Tonga signage by Chinese motel owner 
The local people in the area do not read or understand Mandarin or other Chinese languages. As discussed below, inability to read Chinese does not really matter as local people attach their own meanings to the Chinese characters. The use of Chinese on the signage is both an attempt to appeal to the fellow Chinese nationals and a marketing strategy that applies to the Chinese-Zambian business context. Our interactions with locals in research sites in both Lusaka and Livingstone rural areas suggest that Chinese businesses are associated with affordability. The Chinese businessman has, by using both Chinese and Tonga, accomplished many things indexically and symbolically. Though the Chinese characters are not consumed linguistically by Zambians, they have come to symbolize, and hence are 'read' as representing affordability and bargains. This meaning is embedded in the established sociocultural histories that have come to bear between the Chinese and Zambians over the decades. Interviewees also told us that people wanting directions to an 'affordable rest-house,' are told to look out for a signpost with unmistakable 'Chinese words.' The signpost with a Chinese script is also used as a reference point to various locations in the remote villages and farm smallholdings in the area.

Evidently, although there are Tonga and English words on the signage, which some local people are familiar with, the focal point of reference is the 'out of place' Chinese characters. The meanings are not merely in the conventional or 'known' symbols, but more in the imbued meanings associated with the different semiotic materials and in this case, Chinese writing, which is an 'unfamiliar' occurrence in the area. It has been argued in the literature that literacy in multisemiotic media entails 'a person's ability to make/interpret meaningful signs in a particular representational modality (e.g. print, image, film)' (Narey 2009: 2). In the context of Figure 1, it is the unfamiliar and thus 'non-literate' script to the locals, that gives meaning to what Pumuna Inn entails - an affordable lodge where one can enjoy the comfort of Chinese hospitality.

\section{Oral linguascaping and place semiotics}

Following Stroud and Jegels (2014) and Pennycook (2010), it can be said that, although in the study areas signs are often unmarked with written language and place names, they are reimagined and linguascaped in oral narrations. The lack of marking, for example, is repurposed as a point of reference ('You'll see a board with faded/no markings'). The repurposed material would range from 'discarded' wood to metallic (iron) sheets. Metallic sheets made out of leaky roofing material or cut out of vehicle body parts are often repurposed for signposts, as in Figure 2. From a West-centric perspective, these signs might be described as depicting the poverty of the area or the owner of the farm. To the locals, such material forms part of the semiotic ecology to which navigation references are made. The reference to such signs included descriptive adjectives such as 'You'll see a rough-edged/metal with teeth.' Figure 2 is an example of a sign with a place name on a repurposed piece of metal sheet from the body of a vehicle. 


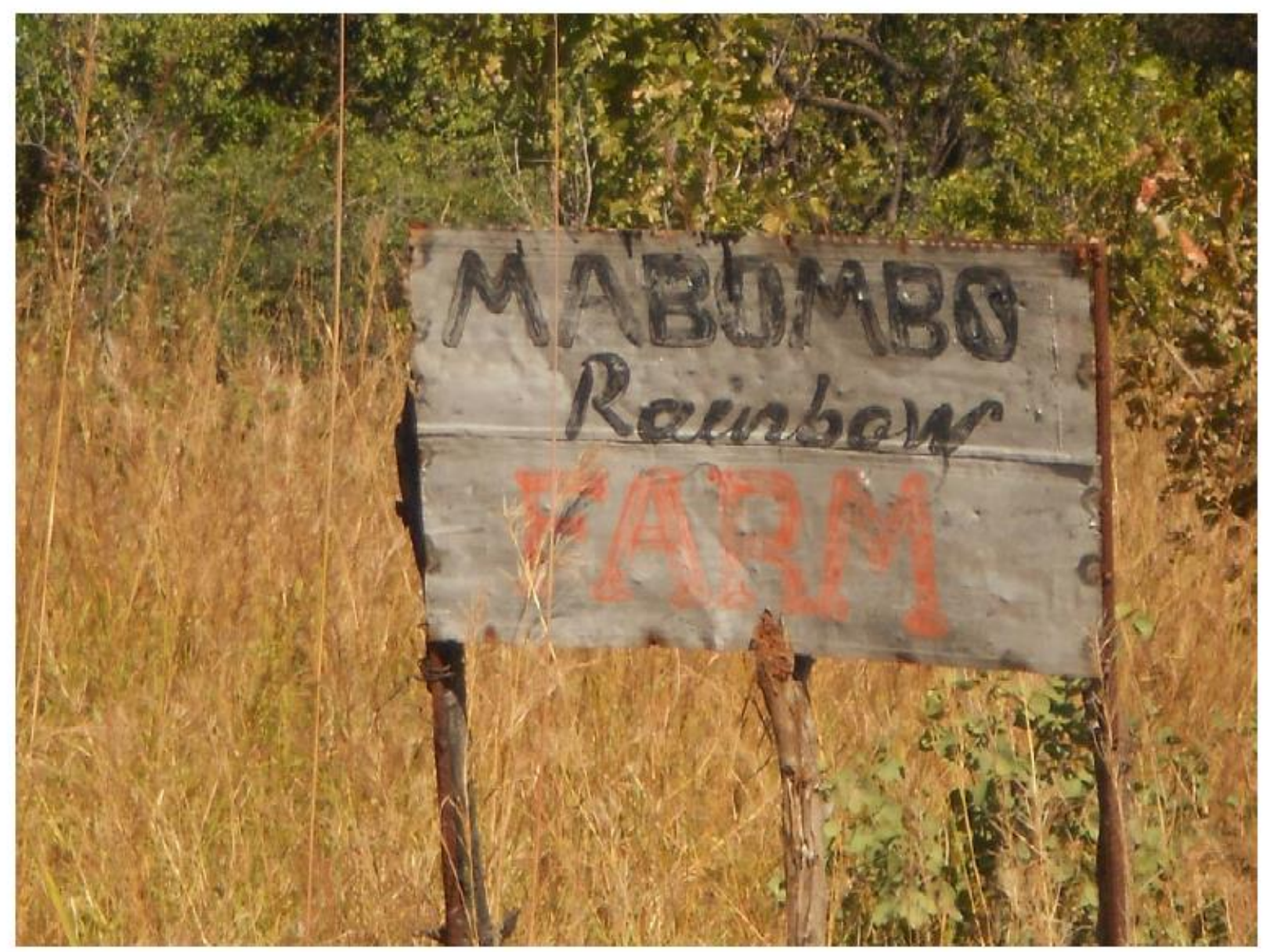

Figure 2: Signage in the bush with place name

The emplacement of the sign is 'supposedly' right on the farmland it indexes - the 'Mabombo Rainbow Farm' - but which is nowhere in sight. Its indexicality is symbolically expressed by Scollon and Scollon's (2003) geosemiotics and what we shall term 'out' of place semiotics in that the farm is not in the vicinity of the sign. The sign is also used as a reference point for other farms and villages in the vicinity. We found a number of such signs which appeared divorced from the place they indexicalized, until one listened to the oral-language remediation, which realigned the sign and place. The sign in Figure 2 is supported by three small poles which match the materiality of the immediate environment. The small poles were apparently appropriated from the surrounding bushes. Not much extra information is supplied by the sign with regard to, for example, the direction one may take to get to the owner of the farm. In fact, the sign has not been emplaced anywhere near the feeder road into the farm. The sign is designed to be an appendage of oral information which brings it to life and gives it meaning and direction. In line with Stroud and Jegels' (2014) and Aronin and ÓLaoire (2012) idea of semiotic landscapes as embedded in local material culture, we found that a person who wants direction to the farm will be told to look out for a metal sign with 'roughedged /metal with teeth,' and which direction to take from there and for how long. It is unneccessary to say look out for a signpost on which is written 'Mabombo Rainbow Farm' since it is the only sign of its kind in place along that stretch of the road. Given that it is in a rural area, chances are also that some of the interlocutors may themselves not be able to read, let alone spell out, what is 
written. It could be that the sign has been used to merely name the place, hence stamping a symbol of ownership and by implication a deterrent to any potential encroachment. If one goes by what Scollon and Scollon (2003) say about the materiality of the sign with regard to durability and permanence, one might conclude that the emplaced sign in Figure 2 is temporary; however, the patrons of these landscapes confirmed that the sign has been emplaced in space and time for as long as they can remember. The repurposed weathered materials used for the signage are testimony to its age. Even if the sign was to fall off, we were told, people would find another use for it, such as refashioning it into a frying pan or charcoal burner, which we found was common practice in this rural-scape. If it was discarded by the roadside, they would find another way of describing it ('You'll see rusted metal by the roadside').

\section{Placemaking as social construct}

Pennycook (2009, 2010), Stroud and Mpendukana (2009, 2010) and Stroud and Jegels (2014) have argued that place and contexts are not static backdrops to which images and written signage are attached. They are dynamic and amenable to change with the meanings being generated. Interlocutors' imagination and revisualization of 'unsigned' semiotic material or faded signage are critical components of oral linguascaping. Signs with faded ('defaced') inscriptions, as depicted in Figure 3, were observed in the rural-scapes of the study areas. The one in Figure 3 was on the Livingstone to Zimba road. The sign's inscriptions have long been erazed by the area's harsh weather conditions. Like the sign in Figure 2, Figure 3 looks 'unplanned' and has blended in with the natural environment in which it is found. A closer examination reveals that the sign has been overlaid with another layer of paint, but we could not get confirmation of this from interviewees. Whatever the circumstances that may be attributed to this sign, one thing is clear about the linguistic/semiotic landscapes of this rural-scape: the extensive use of signs and signboards without written language. While Scollon and Scollon (2003) have pointed out that inscription conveys meaning, Pennycook (2009, 2010) suggests that it is people who reinvent the environment and infuse meaning to the objects and artifacts in it. The lack of inscriptions on Figure 3 does not necessarily take away its value as a 'sign' and its qualities of indexicality. The absence of definitive inscriptions provides a 'blank' space for multiple repurposing, opening up the possiblity of multiple meanings to be created around it by interlocutors through oral-language mediation. Thus, using Bakhtin's (1981) metamorphosis or indeed Bolter and Grusin's (2000) repurposing notions, the sign with faded inscriptions constantly re-evolves to assume different semiotic functions to which it is repurposed as determined by interlocutors. 


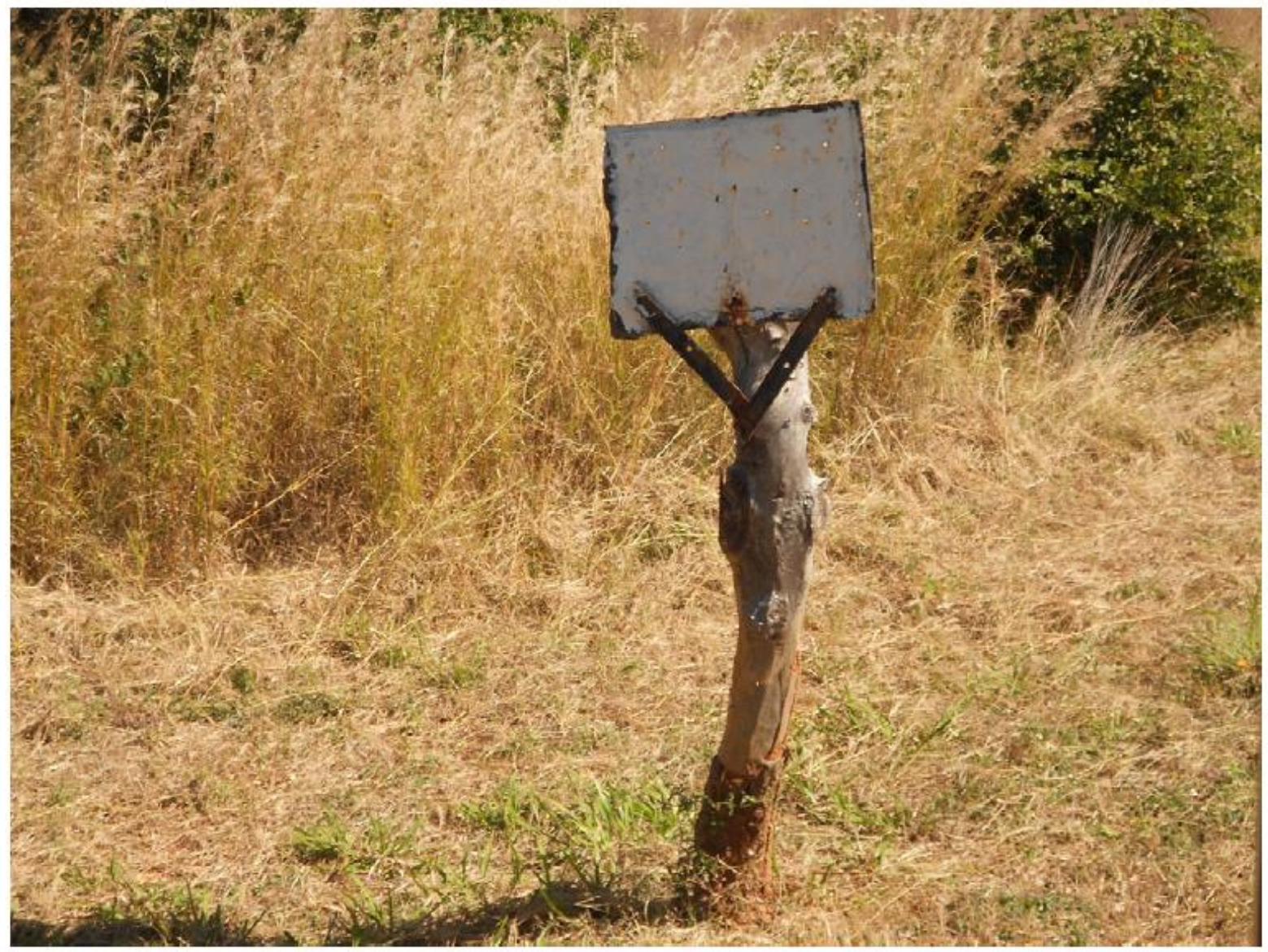

Figure 3: Faded signage

From walking interviews with locals and participant observation, it became apparent that the sign which was meant to be read, slowly transformed into an oral-visual semiotic that indexes 'meaningful' space in more than written words could have potentially accomplished to the mobile users navigating to various places. To some, it is the meeting point; to others, it is a reference point for traversing the space to other places. The multiple meanings attached to the sign are illustrative of the pliability and mobility of oral language, which is used to give shape and meaning to the figure during the process of place making. The shared socio-cultural histories and memories of the dwellers of these landscapes have given rise to a shared use of this sign, in a dynamic and resourceful way, without inscriptions. One informant, a patron of the area, noted that the sign is used to mark out the area and that people use the sign to give multiple directions to visitors. In his own words, the informant indicated: 'Even when the sign had inscriptions on it, we did not refer to the inscriptions but the signpost.' This was confirmed by paticipant observation which revealed use of signs but without 'reading' the words on them. The words are 'translated' and 'transformed' into local discourses such as mau/malembo a mucizungu or a muciChinese ('writings in English or in Chinese'). 


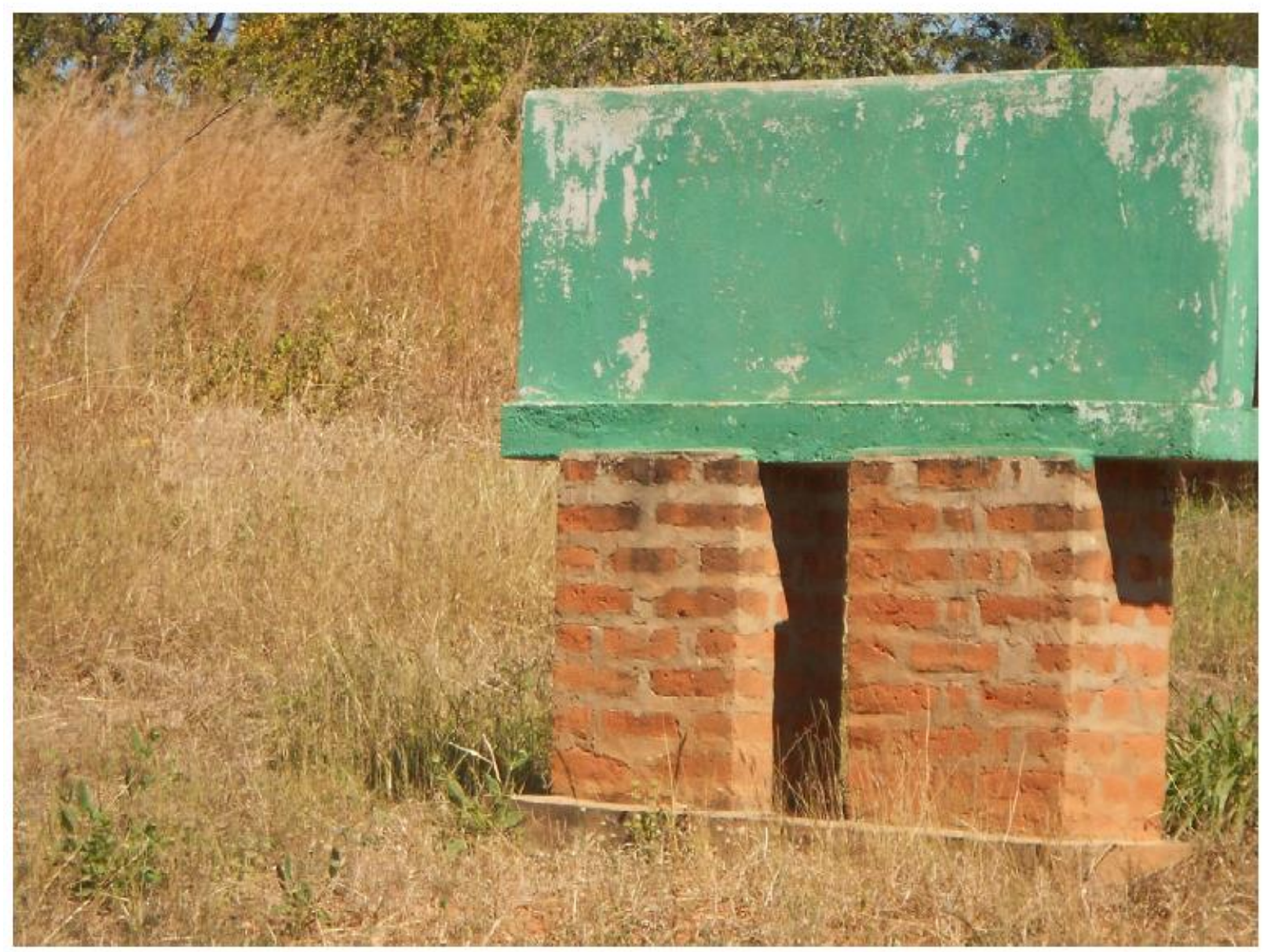

Figure 4: Signage without written language

Together with other inscriptions, they are given new meaning in the discursive imagination and revisualization of place by interlocutors. The translation and interpretation of meaning from the inter-relations and co-occurrence of verbal inscriptions, artifacts and objects in the environment, is a function of socio-historical knowledge and cultural materialities. This is in line with Pennycook's (2010: 143) argument, citing Soja (1989: 79-80), that 'the organisation and meaning of space is a product of social translation, transformation, and experience.'

The sign in Figure 4 augments the claim that, even without any written verbal messages or images, faded signage is repurposed for multiple meanings. Supported by two pillars built out of locally baked bricks, the sign stands conspicuously to the consumers of the linguistic/semiotic landscape. The sign's concrete is painted green and is relatively large, with the potential to carry multimodal signage. Strangely, however, the sign does not contain any verbal or iconic inscriptions on it, despite having been in place for over a year.

Conventionally, the sign does not fully index the school for which it was emplaced. To the left of the sign, in the foreground (not shown in the picture), is a path to a school and this sign should have had inscriptions on it about this particular school. In its current form, the sign can be said to be symbolic of the socio-economic dynamics of the school, a typical sign of neccessity (cf. Stroud and Mpendukana 2009). We were told that funding ran out before something could be written on the 
concrete, as there were more pressing needs for the school, such as buying textbooks. However, as argued above, the signage does not need written language on the concrete to direct one to get to the school. The researchers found their way to the school without difficulty using the 'Green Concrete' as a point of reference to directions given orally. This sign, like those in Figures 2 and 3, keeps undergoing the process of repurposing so that it is not just the embodiment of the sign itself ('You'll see a green concrete') which is used for oral meaning-making, but more so how it is reused in relation to other objects and artifacts for different meanings and placemakings. The meanings associated with it differ depending on what interlocutors want to communicate, ranging from being a sign to index the presence of a school to symbolizing the presence of a clinic or villages nearby. From the illustrations in Figures 1-4, one can postulate that the lack of written language on signage does not impair signmaking; if anything, it makes the act of placemaking a very creative endeavor in which the written words, if available, are ignored or become additional semiotic material on which oral linguascaping is produced and consumed. Conventional signs, especially those with written words, become part of an aggregation of semiotic material in the semiotic ecology on which new meaning is constructed.

Respondents said that trees, rivers, mounds, anthills, buildings and prominent personalities (including those who had long passed on) within these rural-scapes are used as semiotic resources to index the different meanings being referred to. People in these rural-scapes deploy oral linguascaping to make visible and salient particular semiotic features in the ecology of landscapes. However, these features are constantly being reconfigured, enhanced and replaced by both nature and human agency. Some trees are cut, and over time twigs turn into big trees; anthills are eroded; galleries turn into streams. This prompts local people to constantly make changes in choices of semiotic resources to use in their narrations of place. The changes in semiotic features in time and space are drawn upon as the new or additional semiotic material in the ever-changing semiotic environment (Pennycook 2009, 2010). The ecology of the semiotic landscape is dynamic and is constantly changing leading to different constructions of space.

Pennycook (2010: 142-143) cites Cannadine (2000: 188) thatlandscaping is produced not only by planting, cutting, diverting and shaping (landscaping) but is also 'the process whereby those trees, rivers and flowers become invested with meanings and morals and myths and that the process is as much a matter of perception and politics ....

In rural Livingstone, one respondent recalled how, long ago, they used to locate the place of worship by referring to the open fields, but now a burial site has replaced the open fields. They now locate the church by referencing the burial site and/or 'where there used to be open fields.' In Chongwe, outside the city of Lusaka, one informant reported how the same place is referred to by many signs/points of reference: 'where there are many mango trees'; 'where there are vicious dogs'; 'where the house has iron sheets'; etc. This illustration shows the subjective nature of the narrative representation of space. Each of the semiotic resources is evoked 
based on the individual's ideology, experiences and oftentimes, preferred reference points. The reference to 'the vicious dogs' might be influenced by fear of dogs or a previous encounter with these dogs, while referencing the place by use of the sign 'mango trees' leads us to think of love for the mango fruit.

The notion of repurposing, together with the semiotic ecology of landscapes as defined in this article, brings to life Bakhtin's (1981) notion of dialogicality. These ideas unravel how semiotic materials are constantly reimagined as new interrelationships across the various semiotic objects, whether natural or manmade, and are revisualized for different meanings. The oral-language remediated realignment of the 'dialoguing' semiotic objects, artifacts and cultural material in place gives meaning to, and is in line with arguments about the social construction of place in which multiple semiotic materials are deployed for meaning-making (cf. Stroud and Mpendukana 2009, 2010; Pennycook 2010).

We are mindful that narration of place is limited by material conditions (Stroud and Mpendukana 2009, 2010). 'Limitation' is not here understood as, say, a rural community having a diminished capacity for sign- and place-making compared to urban areas. Rather, it is the case that a 'walk in city-scapes' and a 'walk in ruralscapes' entail different experiences and accounts in narrations of space, owing to different objects, artifacts and cultural materialities in place. We can also contend that, through repurposing of the semiotic materials at hand, people transcend the constraints imposed by material conditions to stretch the purposes and the meanings of the semiotic material in place beyond what they are known or were originally designed for. Just as the sign in Figure 2 looks like a metal signboard cut from the body of a vehicle, the sign in Figure 5 is made from cardboard cut from a box. The signage is emplaced along the road leading to Chalimbana College in Chongwe rural. It was emplaced by one of the farmers in the area who is involved in maize and poultry farming.

Figure 5 speaks to both the materiality and the minimalist approach to inscription and signmaking in rural-scapes. The material conditions, as deduced from both Figures 2 and 5, could be taken to indicate poverty or a lack of 'literacy,' but both look 'professional,' not in the sense of Western/European materialities of neon lights and 'factory' measured signboards, but in a marketization/selling sense as seen in the use of different color contrasts and font sizes and types, which also suggests levels of visual design 'literacy.' Orchestrated by the interplay between the concept of business necessity and the socio-economic situation, the rural chicken and maize farmer constructed the signage using repurposed material within his milieu. 


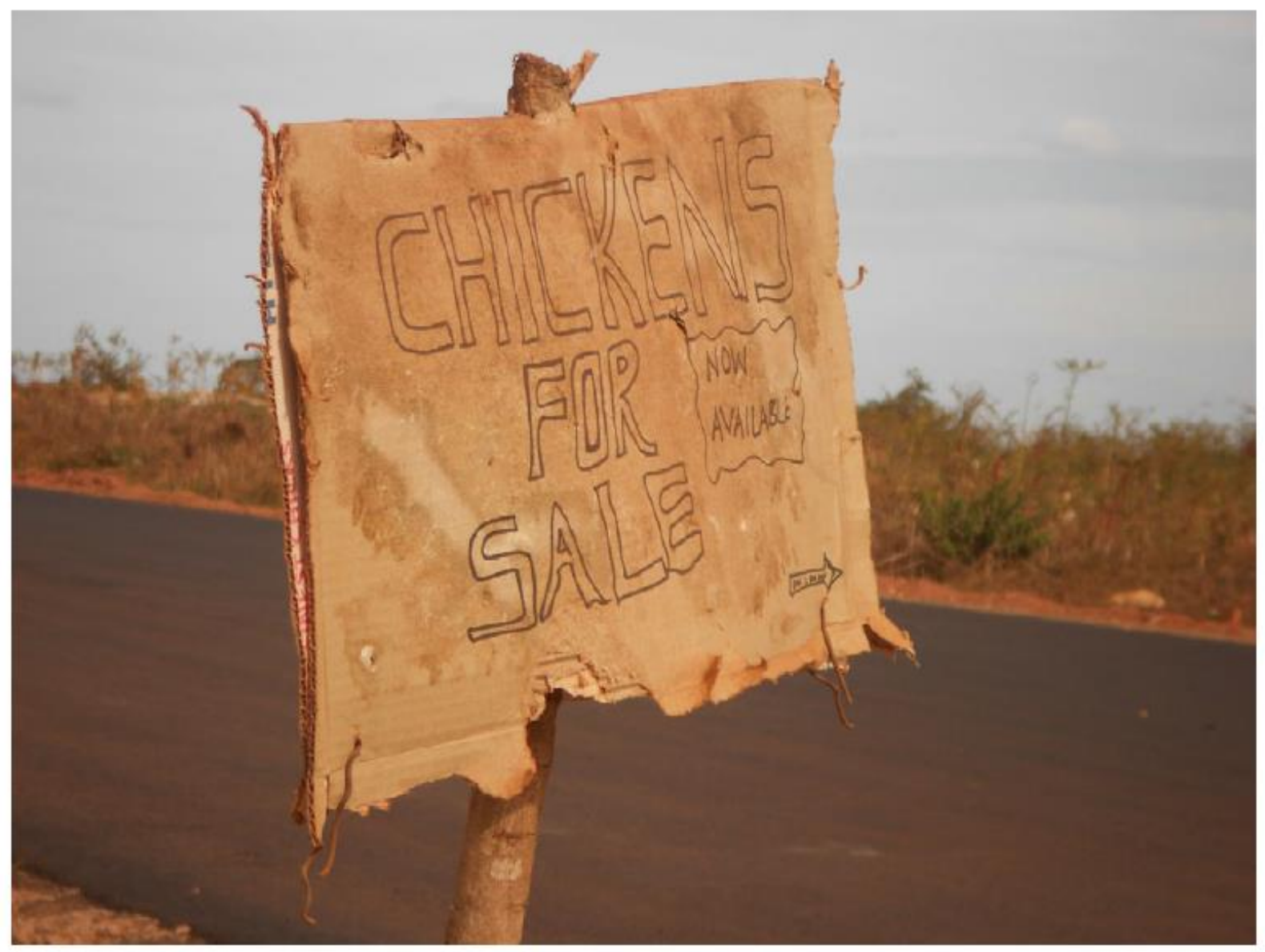

Figure 5: Signage with advertisement for chicken sales

The visibility and salience of the sign has been borne by the use of upper-case letters and the elevation required to keep the sign in sight of motorists. The use of the icon (arrow) is equally productive to index the direction in which can be found the place where the chickens are sold. In this oral linguascaped environment, the arrow is also reversible to index the other farm on the opposite side ('The farm is in the opposite direction to where the arrow is pointing'), and to the local village communities in the vicinity ('You'll see a signboard with an arrow pointing left, but go straight ahead another two kilometres and the village is on the left one kilometre from the main road').

Following Kress and Van Leeuwen's (2006) grammar of visual design, particularly regarding informational order on the sign, the semiotic resource that bears the central message in Figure 5 has been centered while the agency has been accentuated by the inscription just slightly to the right of it, caged in a drawn square, reading 'NOW AVAILABLE'. Being on the village 'highway,' the inscription 'NOW AVAILABLE' is designed to inform speeding motorists that stopping over will be worth their while, because it is perhaps a guarantee that, in the local lingo, 'village priced' (affordable) chickens are available at the farm. 


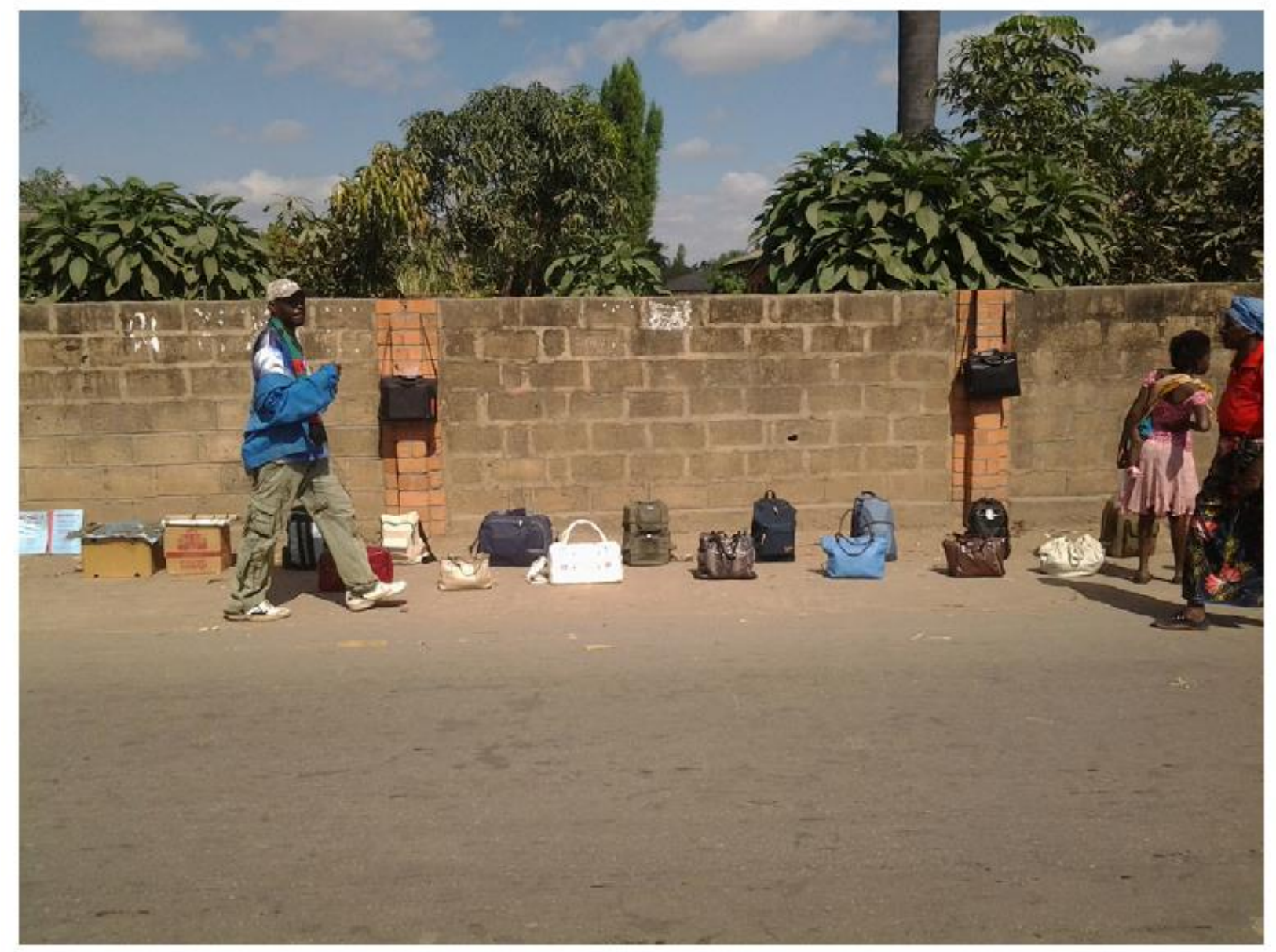

Figure 6: Image of an open market

The next question is why a semi-commercial farmer who can afford professional signage repurposed some discarded cardboard, together with glue and rusted wire from a chicken coup mesh, for a signboard. We found that in these rural areas (perhaps like anywhere else) people are resourceful and nothing gets thrown away, as people are in the habit of repurposing material at hand (Prior and Hengst 2010). Also, commercially done signboards are associated with luxury and high cost, and hence with the idea that the chickens are equally as expensive - which would be bad for business.

Figure 6 illustrates Pennycook's (2010: 143) argument that the objects and cultural materialities on which signmaking is created are 'not only about placement, but also [about] ... the construction of meaning from the movement.' Depending on real or imagined activities that take place at the space, it is described as a market, a bus stop or a football field.

The image we have named an 'open market' in Figure 6 points to openness of space and the non-restrictedness in the normative creations of oral-linguascapes. More importantly, Figure 6 illustrates how space is appropriated and reinvented by individuals, and supports the argument that the semiotic environment is endlessly under construction (Pennycook 2010). The open market is also seen in the fact that small-scale businesses that were observed operating at the site had no price tags on the merchandise, forcing consumers and business owners to transact prices orally in 
a language familiar especially to the consumer. Lack of any sign to index the sort of business being conducted can be said to be a result of a temporary conquest of this space by the vendors. At any time, we were told, with the arrival of boys from the surrounding areas, the space can be reconfigured and hence repurposed into a football field, or into a bus stop with the arrival of a bus. Indeed, the kinds of bags hanging on the fence and lying on the ground suggest that the place is also used as a 'long distance' bus station, as testified by an informant. But, for now, attention is on what is being sold at the market. On the edge of the image is a box on which lies dried pumpkin leaves, a delicacy cherished by travellers from urban areas where it is in short supply. Stacked against the wall are Grade 7 and what appears to be Grade 9 study materials, all for sale. In the background behind the wall are glimpses of modern-structured houses, and at least two of the well-tended trees in the yard appear to be exotic.

As noted earlier, linguistic landscaping is not merely about emplacement of the fauna, flora and other objects in the environment, it is also about the conscious acts of investing them with meanings (Pennycook 2010). Figure 7 draws our attention to, and accentuates, how shrubs and trees as well as the elevated skyline, that is skyscapes, are reimagined for signmaking and meaning.

As the image in Figure 7 shows, there are no scripted signs - billboards, road signs, place names - in this landscape to which patrons of the area can refer. But, thanks to the locals who provide oral information about the kinds of trees, the position of tree branches, grass and shrubs and outlines of hills and mountains in the distance in relation to one another, people are able to extend the explanatory power of the ecology of semiotic material to narrate place and give directions with consumate accuracy. For example, from the point where the researcher who took this picture stood, the thick shrubs and tree in the distance, and a slightly visible protruding rock 'with a mouth' were reference points to reach the next village.

It was also interesting that even where there was written language on a signboard, people (including those able to read and write) would often 'read' their own message, or add more information to it, rather than refer to what was written on it. Thus, they produced their own statements or narrations of space. As a way of illustration, one of the authors asked two young women and a primary school student in Nyanja, the local language, on a road bordering urban and rural Lusaka Province towards Chongwe District, about how to get to the 'Monastery of St Clare.' They all looked at him bewildered and they said they did not know the place. However, when he said Kwamene kuli masistas 'Where sisters/nuns live', they were able to narrate the place thus:

Muyende cabe apo [pointing in the direction]. Muzapeza cibodi [signboard], muyende kuright. Muzaona mitengo ya mango kuright na maflowers kuleft. Two-three handeredi [hundred] meters mwafika.

'You go that way. You'll see a (sign)board and turn right. You'll see mango trees on the right and flowers on the left. Two-three hundred meters you'll find the place.' 


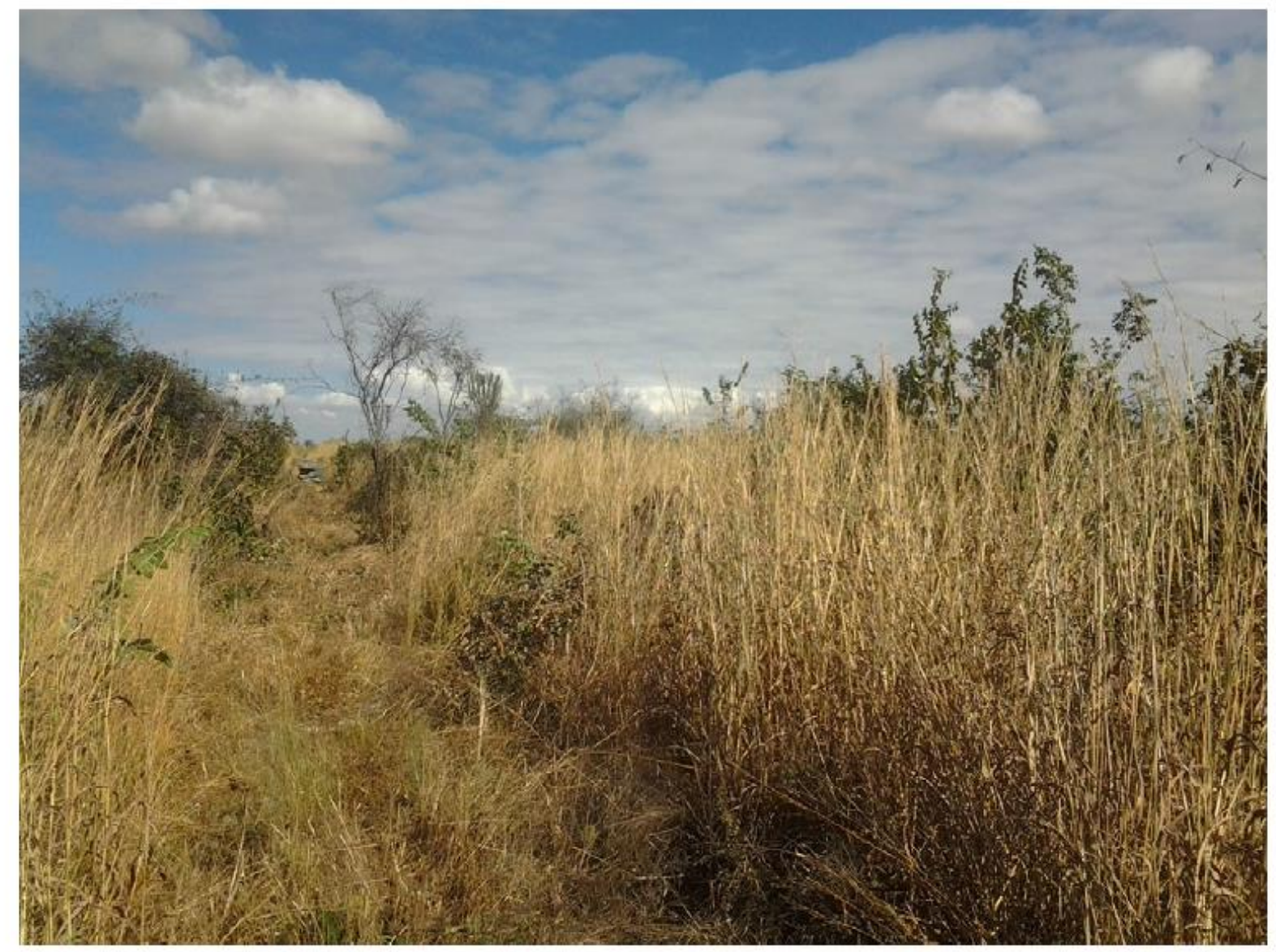

Figure 7: Image of village path and sky-scape as signage

What is interesting is that they referred to a signboard without saying what was written on it. The signboard had 'Monastery of St Clare' clearly written on it. However, through oral-linguascaping they created meaning using the 'empty' signboard, trees and flowers and distance. Thus, the fact that they seemed oblivious to the words on the signboard did not affect the quality of the information they gave, as the researcher was able to make out from their oral input that the 'empty' signboard, trees, flowers and distance all led to the 'Monastery of St Clare.' Evidently, to these locals, that the signboard is written had little communicative value as the real power of communication lies with the spoken word, which is used to realign, and hence re-'sign' the different semiotic materials in place for various directions/meanings.

\section{Summary and conclusion}

We can conclude that sign- and place-making is a dynamic and ongoing endeavor as space is continually imagined, reimagined, created and reinvented as people draw different meanings out of the semiotic material in place as interceded by communication needs, memory, sentiments and perceptions of producers and consumers. 
Scollon and Scollon (2003: 138) make an interesting argument that indexicality is in the material itself rather than in its cost or whether it is durable and permanent or not. Applying this argument to rural-scapes in the study area provides interesting insights, principally because most semiotic resources in use are emplaced by nature, and therefore 'permanent.' Evidently, 'permanency' needs to be understood in terms relative to a multiplicity of the meaning potentials of a given sign. Moreover, changes in environmental factors induce changes in the description of what was construed as a permanent feature. A faded signpost can be described as 'bright' on a sunny day but simply as 'a signpost' on overcast day. Similarly, trees and grass as semiotic resources may be described as 'green' or 'dry/brown' depending on season. 'Permanency' is also relative to what speakers perceive as salient to achieve a particular communicative goal. Different people may use different reference points and hence recognize different features of the semiotic material in a theater of signage to give directions. Salience and visibility of signage are not necessarily determined a priori. What we have shown is that, in the rural areas studied, oral linguascaping enables people to easily repurpose ideas, socio-cultural knowledge and materialities, and other semiotic materials in place, for meanings and utility functions they are not known or designed for. Landscapes and signage are not mere consequences of emplacement: their meanings, whether in memory, written, iconic or as objects and artifacts in space, are products of discursive reintegration and reinvention of the semiotic environment.

Including repurposing in the analytical toolkit helps to account for the expanded meaning potentialities embedded in the different features of the semiotic material in the semiotic ecology of sign- and place-making. This gives meaning to Kress's (2010) argument that there is no end point as to what constitutes a semiotic system, as the semiotic resources at hand are amenable for reuse for different meanings and purposes; they are continually being reinvented and hence continually on the move during the narration of place (Pennycook 2009, 2010). Repurposing becomes critical in understanding not just how people remediate the available semiotic resources, but also how they reuse them for different and multiple sign- and place-making purposes.

The notion of repurposing also enables us to explain how, even in the context of limited or no scripted material, people use their human creativity to rework the semiotic material at hand for different meanings and purposes. To borrow from Pennycook (2010: 143) following Milon (2002), the expressions that construct the landscapes are not mere verbiage that 'cover up' the semiotic material in place, 'whose interpretation is complete ... [they are] part of the mobile expression of the changing [spatial] face.' The mobility and sign-making potentials of semiotic material are further extended through repurposing prior discourses, objects and cultural materialities for new uses and meanings.

The study shows that the producers and consumers of signage are active managers of the ecology of semiotic systems in place for meaning-making. They use it to discursively cultivate semiotic relations of materials in the environment for different meanings. This is in line with Pennycook's (2009: 310) argument that 
landscape is 'not a canvas' but an 'integrated and invented environment' which is 'constantly under production.' The agentive nature of sign-making, as described above, means that linguistic/semiotic landscaping is individualized and participatory at the same time. It involves creativity in the reusing of semiotic material that facilitates sign interpretation in mediated meaning-making. Meaningmaking is understood against the backdrop of varied contexts and the diverse available semiotic material. The meanings generated by particular semiotic affordances may vary from individual to individual. For example, it is possible for two individuals to provide different directions based on one sign.

Following the multimodal turn in linguistic/semiotic landscape studies, there is a need to move beyond the idea that signs need to be 'visible' (to the naked eye), to a more process-material approach. Also, there is a need to focus on multisemioticity in meaning-making, that is, the co- and inter-relationships of various semiotic material in the construction of particular meanings (Pennycook 2010). The focus on multisemioticity entails an understanding that features such as tree linings, over-hanging branches, different kinds of paths - single human tracks, two-tracks made by ox-drawn carts as well as different kinds of soil and related flora and fauna - be seen as potential semiotic affordances and hence reference points in the semiotic landscaping. The study of linguistic/semiotic landscapes is more than a study about what we read and see in signage; it is also about the dialogicality and interaction of the various semiotic materials, visible or invisible, outside or in the immediate contexts. These are brought to life through negotiated meaning-making between interlocutors as they make sense of the co- and inter-relationships of various semiotic materials, of which they are also a part.

The notion of repurposing enables us to appreciate how sign- and place- making in rural communities is not necessarily impaired by the limitations or absence of material affordances such as signposted streets, place names, neon lights and so on often found in urban areas. We saw examples of prior signs and existing semiotic material being repurposed and redirected in new contexts of use for diverse meanings. Old and faded signs are renewed through oral language, which is used as a mediator to realign different semiotic material into diverse referents and for different meaning. In this conceptualization, the removal or absence of known objects and cultural materialities becomes the new point of reference ('Turn right at the signboard on which was written "Sipalo Butchery") in the discursively (re)constructed environment.

If, as argued by Pennycook (2009: 308), 'trees, rivers and flowers become invested with meanings' during landscaping, their inclusion in narration is a discursive act of the spatial realization of place. In this connection, we have used the notion of repurposing to account for how producers and consumers of signage rework the spatial environment in order to transcend the limitations of material conditions through strategic selection of semiotic material for redeployment for new meaning. Thus, through the strategic selection, realignment and shifting of semiotic material, over-arched by years of socio-cultural solidarity and complex 
histories which thrive on the repurposing of semiotic material, interactants are able to readapt objects and ideas to recreate place, contexts and specific meanings.

Finally, the semiotic landscapes in the rural, oral-dominant communities under study suggest a somewhat different taxonomy of 'signs' for place making compared to urban areas. Just as 'the parameters of the local urban ecology are reflected in the design and placement' of semiotic material in urban areas (Stroud and Jegels 2014: 187), it can be argued that the local, rural semiotic material determines the semiotic ecology in place in rural communities.

No doubt the predisposition of people in the rural-scapes discussed in the study, to use existing or past physical attributes of the environment, can be said to be common even in urban areas. However, with little or no man-made public signage in these rural areas, there is an additional need for creativity in how oral narration is deployed to account for mutual relationships between the interactants themselves, and with their semiotic environment. In this regard, we showed the ways in which faded orthographies, names and texts, and removed objects and socio-cultural materialities (e.g. 'What used to be a graveyard/Sipalo Butchery') are reimagined, and how linguistic and scripted signage (including icons and the shapes of letters and characters) are ignored or translated in local expressions and reinterpreted with other kinds of semiotic material for sign- and place-making.

The study suggests an extended taxonomy of 'signs,' which includes boundary markers (e.g. fences, hills and mounds, ditches [man-made or natural], concrete posts, names of farms, beacons [salient topographical features], major junctions, street names or names of shops [used as points of orientation], etc.). The semiotic ecology approach to studying the linguistic/ semiotic landscapes in rural-scapes, helps to highlight the extended repertoire of semiotic materials in place. It also highlights the multisemiotic nature, and the different processual characteristics of meaning-making in linguistic/semiotic landscapes even in oral-language dominant rural communities. Ultimately, the study shows that, irrespective of the limitations of material conditions, people in rural-scapes (like those in urban areas) repurpose available semiotic materials to extend their meaning potential and, in the process, constantly reinvent the semiotic environment and their relations with it for sign- and place-making. 


\section{References}

Aronin, Larissa and Muiris ÓLaoire. 2012. The material culture of multilingualism: Moving beyond the linguistic landscape. International Journal of Multilingualism 10: 225-235. doi:10.1080/14790718.2012.679734

Backhaus, Peter. 2005. Signs of multilingualism in Tokyo - a diachronic look at the linguistic landscape. International Journal of Sociology of Language 175/176: $103-121$.

Bakhtin, Mikhail. 1981. Dialogic Imagination (Caryl Emerson and Michael Holquis trans.). Austin, Texas: University of Texas press.

Bernstein, Basil. 2000. Pedagogy, Symbolic Control and Identity. Boston, Massachusetts: Rowman \& Littlefield Publishers.

Bolter, J. David, and Richard Grusin. 2000. Remediation: Understanding New Media. Cambridge, U.K.: MIT Press.

Briggs, Charles and Richard Bauman. 1992. Genre, intertextuality, and social power. Journal of Linguistic Anthropology 2: 131-172.

Cannadine, David. 2000. Class in Britain. London: Penguin.

Cenoz, Jasone and Durk Gorter. 2006. Linguistic landscape and minority languages. International Journal of Multilingualism 3: 67-80.

Cenoz, Jason and Durk Gorter. 2009. Language economy and linguistic landscape. In Elana Shohamy and Durk Gorter (eds.) Linguistic Landscape: Expanding the Scenery. New York: Routledge. 55-69.

Central Statistical Office [CSO]. 2010. Zambia 2010 Census of Population and Housing. Lusaka, Zambia: Central Statistical Office.

Fairclough, Norman. 2003. Analyzing Discourse: Textual Analysis for Social Research. New York: Routledge.

Fill, Alwin. 2001. Ecolinguistics: State of the art. In Alwin Fill and Peter Mühlhaüsler (eds.)

The Ecolinguistic Reader: Language, Ecology and Environment. London: Continuum. 4356. Fill, Alwin and Peter Mühlhaüsler (eds.). 2001. The Ecolinguistic Reader: Language, Ecology and Environment. London: Continuum.

Haugen, Eina. 2001. The ecology of language. In Alwin Fill and Peter Mühlhaüsler (eds.) The Ecolinguistic Reader: Language, Ecology and Environment. London: Continuum. 57-66.

Hiramoto, Mie and Joseph Sung-Yul Park. 2012. Media intertextualities: Semiotic mediation across time and space. In Mie Hiramoto (ed.) Media Intertextualities. Amsterdam, The Netherlands: John Benjamins. 1-10.

Hult, M. Francis. 2009. Language ecology and linguistic landscape analysis. In Elana Shohamy and Durk Gorter (eds.) Linguistic Landscape: Expanding the Scenery. New York: Routledge. 88-104.

Iedema, Rick. 2003. Multimodality, resemiotization: Extending the analysis of discourse as multi-semiotic practice. Visual Communication 2(1): 29-57.

Irvine, Judith 2010. Semiotic remediation: Afterword. In Paul A. Prior and Julie A. Hengst (eds.) Exploring Semiotic Remediation as Discourse Practice. New York: Palgrave Macmillan. 235-242.

Jaworski, Adam and Crispin Thurlow. 2010. Introducing semiotic landscapes. In Semiotic Landscapes. London: Continuum. 1-40. 
Kress, Gunther. 2010. Multimodality: A Social Semiotic Approach to Contemporary Communication. New York: Routledge.

Kress, Gunther and Theo Van Leeuwen. 2006. Reading Images: The Grammar of Visual Design. London: Routledge.

Landry, Rodrigue and Richard Y. Bourhis. 1997. Linguistic landscape and ethnolinguistic vitality: An empirical study. Journal of Language and Social Psychology 16(1): 23-49.

Lanza, Elizabeth and Hirut Woldemariam. 2009. Language ideology and linguistic landscape: Language policy and globalization in a regional capital of Ethiopia. In Elana Shohamy and Durk Gorter (eds.) Linguistic Landscape: Expanding the Scenery. New York: Routledge. 189- 205.

Lefebvre, Henri. 1991. The Production of Space. Oxford, U.K.: Blackwell.

Linell, Per. 1998. Approaching Dialogue: Talk, Interaction, and Contexts in Dialogical Perspectives. Amsterdam, The Netherlands: John Benjamins.

Malinowski, David. 2009. Authorship in the linguistics landscape: A multimodalperformative view. In Elana Shohamy and Durk Gorter (eds.) Linguistic Landscape: Expanding the Scenery. New York: Routledge. 107-125.

Massey, Doreen. 2005. For Space. London: Sage.

McIlvenny, Paul, Mathias Broth and Pentti Haddington. 2009. Communicating place, space and mobility. Journal of Pragmatics 41: 1879-1886.

McLuhan, Marshall. 1964. Understanding Media: The Extensions of Man. New York: New American Library, Timer Mirror.

Milon, A. 2002. Tags and mural in France: A city's face or a natural landscape? In Alain- Philippe Durand (ed.) Black, Blanc, Beur: Rap Music and Hip-Hop Culture in the Franco-Phone World. Lanham, Maryland: Scarecrow. 87-98.

Mondada, Lorenza. 2011. The interactional production of multiple spatialities within a participatory democracy setting. Social Semiotics 21: 289-316.

Mühlhaüsler, Peter. 1996. Linguistic Ecology: Language Change and Linguistic Imperialism in the Pacific Region. London: Routledge.

Narey, Marilyn (ed.). 2009. Introduction. Making Meaning, Constructing Multimodal Perspectives of Language, Literacy, and Learning through Arts-Based Early Childhood Education. New York: Springer. 1-8.

Peck, Amiena and Felix Banda. 2014. Observatory's linguistic landscape: Semiotic appropriation and the reinvention of space. Social Semiotics 24: 302-323.

Pennycook, Alistair. 2009. Linguistic landscapes and transgressive semiotics of graffiti. In Elana Shohamy and Durk Gorter (eds.) Linguistic Landscape: Expanding the Scenery. New York: Routledge. 302-312.

Pennycook, Alistair. 2010. Spatial narrations. In Adam Jaworski and Crispin Thurlow (eds.) Semiotic Landscapes: Language, Image, Space. London: Continuum. 137-150.

Pietikäinen, Sari, Pia Lane, Hani Salo and Sirkka Laihiala-Kankainen. 2011. Frozen actions in the Arctic linguistic landscape: A nexus analysis of language processes in visual space. International Journal of Multilingualism 8: 277-298.

Prior, Paul and Julie Hengst. 2010. Introduction. In Paul A. Prior and Julie A. Hengst (eds.)

Exploring Semiotic Remediation as Discourse Practice. New York: Palgrave Macmillan. 123. Schama, Simon. 1995. Landscape and Memory. New York: Alfred Knof. 
Scollon, Ron and Suzanne Wong Scollon. 2003. Discourse in Place: Language in the Material World. London: Routledge.

Shohamy, Elena and Durk Gorter. 2009. Introduction. In Elena Shohamy and Durk Gorter (eds.) Linguistic Landscape: Expanding the Scenery. New York: Routledge. $1-10$.

Shohamy, Elena and Shoshi Waksman. 2009. Linguistic landscape as an ecological arena: Modalities, meanings, negotiations, education. In Elena Shohamy and Durk Gorter (eds.) Linguistic Landscape: Expanding the Scenery. New York: Routledge. 313-331.

Silverstein, Michael and Greg Urban (eds.). 1996. Natural Histories of Discourse. Chicago, Illinois: Chicago University Press.

Soja, Edward W. 1989. Postmodern Geographies: The Reassertion of Space in Critical Social Theory. London: Verso.

Stroud, Christopher and Dimitri Jegels. 2014. Semiotic landscapes and mobile narrations of place: Performing the local. International Journal of the Sociology of Language 228: 179-199.

Stroud, Christopher and Sibonile Mpendukana. 2009. Towards a material ethnography of linguistic landscape: Multilingualism, mobility and space in a South African township. Journal of Sociolinguistics 13: 363-386.

Stroud, Christopher and Sibonile Mpendukana. 2010. Multilingual signage: A multimodal approach to discourse of consumption in a South African township. Social Semiotics 20: 469-493.

Thrift, Nigel. 2007. Non-Representational Theory: Space, Politics, Affect. London/New York: Routledge.

Thurlow, Crispin and Adam Jaworski. 2014. 'Two hundred ninety-four': Remediation and multimodal performance in tourist placemaking. Journal of Sociolinguistics 18: 459-494.

Urry, John. 2005. The 'consuming' of place. In Adam Jaworsky and Annette Pritchard (eds.) Discourse, Communication and Tourism. Clevedon, U.K.: Channel View. 9-27.

Vandenbussche, Bert. 2003. Remediation as medial transformation: Case studies of two dance performances by 'Commerce'. Last accessed 4 October 2015 at http://

www.imageandnarrative.be/inarchive/mediumtheory/bertvandenbussche.htm

Zabrodskaja, Anastassia and Tommaso M. Milani. 2014. Signs in context: Multilingual and multimodal texts in semiotic space. International Journal of the Sociology of Language 228: 1-6. 